\title{
RADIOLOGICAL CHANGES IN CONTROLLED HYPERVOLAEMIC PULMONARY OEDEMA IN DOGS
}

\author{
WiLliam H. Noble and D.J. Sieniewicz
}

\section{INTRODUCTION}

Pulmonary oEdema is not easily detected or differentiated from other causes of hypoxia in intensive care unit patients. Double indicator dilution techniques have been used to quantitate the amount of lung water. ${ }^{1,2,3}$ These techniques require systemic and pulmonary arterial catheters. The Swan-Ganz pulmonary artery catheter makes the procedure possible in the I.C.U. but we have been searching for less invasive techniques to measure an increase in the amount of extravascular lung water before a stethoscope can detect it. Although arterial oxygenation and lung compliance both fall as pulmonary œdema accumulates ${ }^{4}$ they can be low for many other reasons than odema. Radiological changes are more specific and may be useful in quantitating the amount of œedema. ${ }^{5}$

This experiment was designed to assess the radiological technique in detecting early pulmonary cedema, in differentiating between congestion and œedema, in monitoring the increases of œdema and in determining the effects of CPPV on an already œdematous lung.

After improvements were made in our radiological techniques the radiographic study could detect oedema at an early stage and could be used to follow the increasing lung water created experimentally. However, the conditions for taking these radiographs were nearly perfect while those in an I.C.U. setting almost never are.

\section{MeTHOD}

Six dogs were anaesthetized with pentobarbitone $(30 \mathrm{mg} / \mathrm{Kg}$ with supplements as necessary). The dogs were placed in a supine position and allowed to breathe spontaneously. A special aortic catheter was passed up the femoral artery. This catheter and a pulmonary artery thermistor catheter allowed us to calculate the extravascular thermal volume of the lung $\left(\mathrm{ETV}_{\mathrm{L}}\right)$ which we have previously shown measures the amount of lung water., ${ }^{2,3}$ The $\mathrm{ETV}_{\mathrm{L}}$ technique also gave us values for central blood volume and cardiac output. Arterial blood gases were followed.

AP and lateral chest films were taken with particular care that the dogs were in the same position relative to the film and the film the same distance from the machine head. Initially a portable X-ray unit requiring $0.2 \mathrm{sec}$ exposure at $15 \mathrm{MA}$ was employed. We found the 3 MAS factor was not suitable to stop motion and therefore changed to a unit producing $200 \mathrm{MA}$ with a short exposure of $0.033 \mathrm{sec}$.

Departments of Anaesthesia and Radiology, St. Michael's Hospital and University of Toronto. 


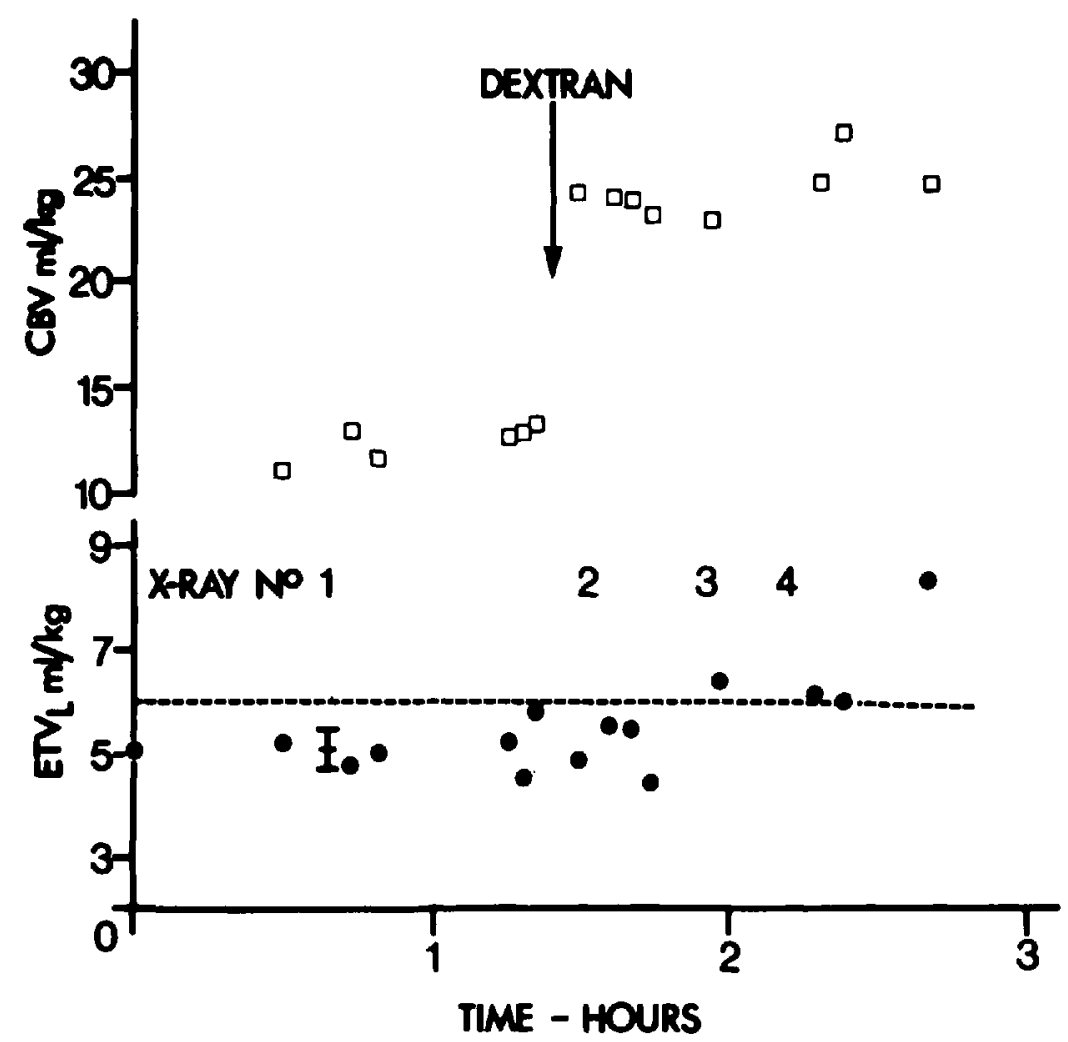

Figure 1. Central blood volume (CBV) and ETV (lung water) are followed as the experiment progresses. Radiographs were taken at the indicated times. An infusion of dextran was started at the arrow and resulted in an immediate rise in CBV and a later rise in ETV $_{\mathrm{L}}$. The mean and 1 S.D. of control ETV $V_{L}$ is indicated. Therefore any point above the 3 S.D. line ( . . . ) is significantly different from control $\mathrm{ETV}_{\mathrm{L}}$.

These factors produced satisfactory radiographs at $70 \mathrm{~K} . \mathrm{V}$. The shorter exposure removed the film blurring and allowed sharp details to be seen.

After control films and measurements were taken dextran was infused to overload the left heart and produce pulmonary oedema. Lung water, central blood volume, cardiac output and arterial oxygenation were followed every 10 minutes as oedema was induced. Randomly numbered radiographs were taken as oedema developed and these were independently assessed by a radiologist who did not have access to information as to when films were taken or to $\mathrm{ETV}_{\mathrm{I}}$, values.

After gross pulmonary oedema had accumulated, CPPV was applied at $15 \mathrm{~cm}$ $\mathrm{H}_{2} \mathrm{O}$ end-tidal pressure and films were taken and measurements repeated.

The radiologist wrote a report on his findings which were only then related to ETV $\mathrm{r}_{\mathrm{r}}$, central blood volume and $\mathrm{Pa}_{\mathrm{O}_{2},}$ values. The radiologist then reassessed the films with the additional information at hand.

\section{REsults}

In every dog dextran overload was successful in producing oedema as measured by ETV $_{\mathrm{I}}$. Figure 1 plots central blood volume and ETV $_{\mathrm{I}}$, i.e., lung water against 


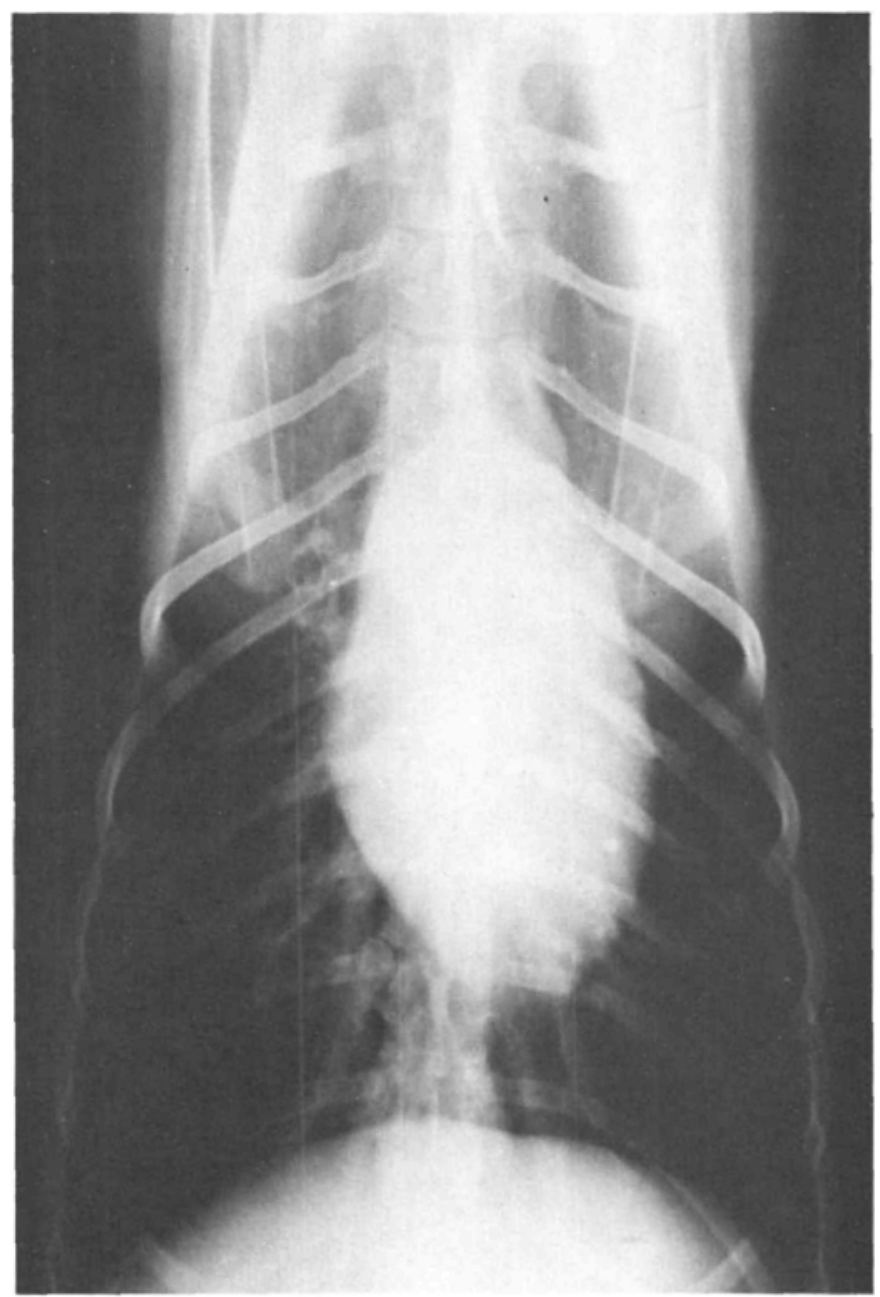

Figure 2. A control radiograph (film No. 1) indicates the narrow dog's chest, a pulmonary vein coming out from the right lower mediastinum and an end-on bronchus and vessel in the right upper lung zone. All radiographs in this paper are from this same dog to allow comparison.

time. As soon as dextran is infused central blood volume immediately increases. $\mathrm{ETV}_{\mathrm{I}}$, does not, immediately, so that radiograph No. 2 taken in congestion must differentiate congestion and oedema. The mean control ETV $\mathrm{I}$, was $5.12 \pm 0.13$ as 1 S.D. The dotted line represents 3 S.D. and therefore the first ETV $\mathrm{I}_{\mathrm{I}}$ that detects oedema occurs after radiograph No. 3 . The radiographs were taken at the indicated times.

The radiologist had no difficulty in placing the films in the correct sequence. Once this was accomplished it was a matter of picking the first film in which oedema appeared. Initially one film had oedema labelled on control studies but this was corrected after the first dog by changing the exposure factors as described above. With good films the radiologist was as good as ETV $_{\mathbf{L}}$ in separating congestion from very early oedema. A pulmonary vein stood out in the control period (Figure 2) was enlarged in congestion (Figure 3) and had minimal blurring of its 


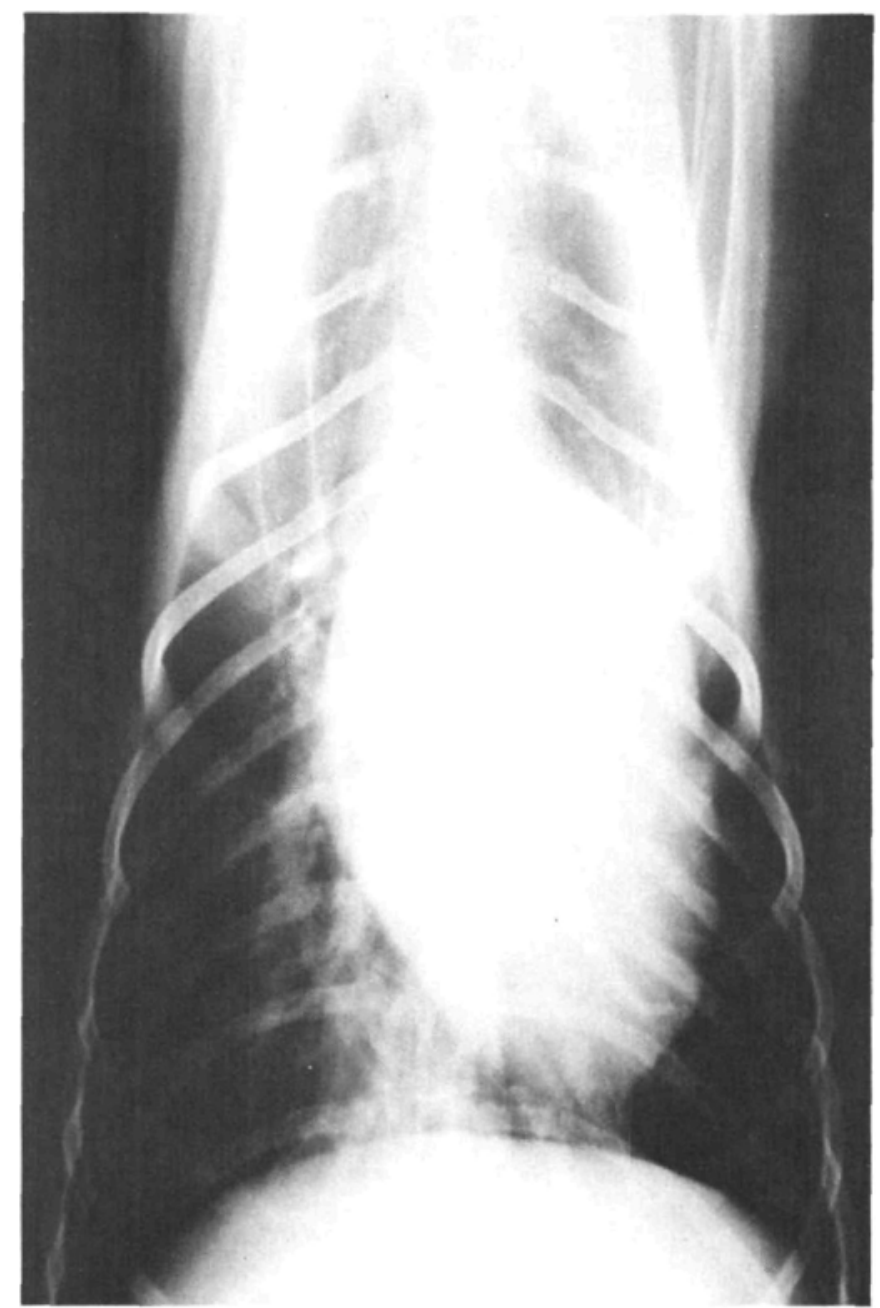

Figure 3. Film No. 2 is in congestion with no oedema detected by the $\mathrm{ETV}_{\mathrm{L}}$ technique. Note the cardiac enlargement as well as engorged vessels inferiorly. The hilar vessels are still sharp. This was considered to represent engorgement or congestion.

border in early oedema (Figure 4). We found that haziness of pulmonary vessels to be the best early indicator of pulmonary oedema. We looked at the heart border, ribs, diaphragm and vertebrae for signs of veiling or haziness in early oedema but found the contrast too great between lung tissue and these structures so that early oedema haziness was not seen. Kerley lines were never seen. An "end-on" bronchus in the control period became smaller as congestion and early oedema occurred. The wall appeared to be getting thicker but on further analysis the apparent increase in wall thickness may have been due to a smaller calibre of the bronchus with pressure from the outside by congestion. Staub, Nagano and Pearce indicated the sequence of pulmonary oedema accumulation histologically. ${ }^{6}$ They found the earliest accumulation of oedema is around the bronchovascular sheath and it is only later that oedema accumulates in the corners of alveoli and then floods the 


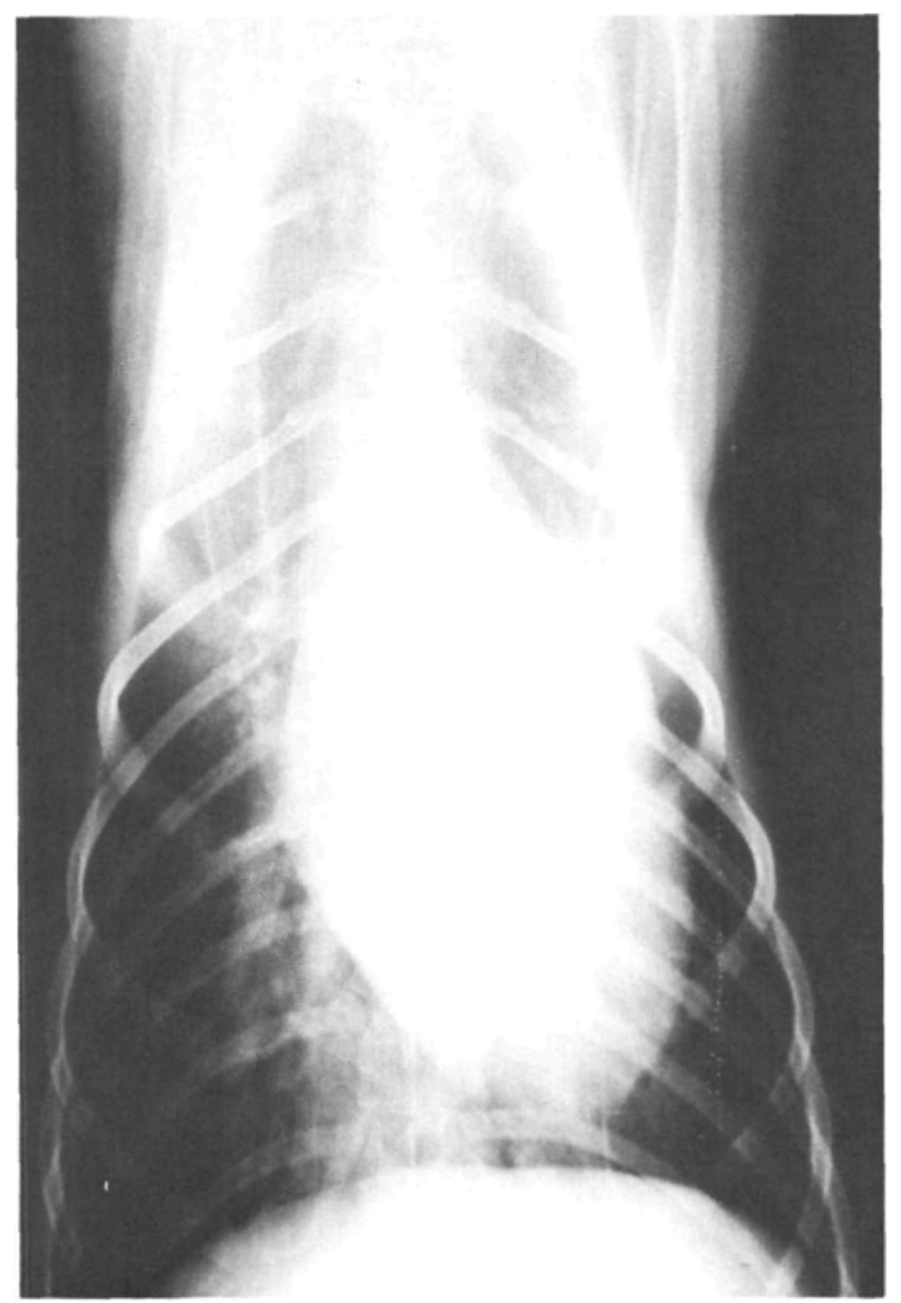

Figure 4. Film No. 3 is in the earliest oedema detectable by the ETV $_{\mathrm{L}}$ technique. There is now an indistinct outline to the vessels and haze at the right hilum. This would be considered to represent primary interstitial oedema.

alveoli. By focusing on the vessels and bronchi we could see this sequence occurring (Figure 5). In the earliest stage of oedema there was blurring of the vessel and end-on bronchus walls. Later, as the alveoli began to fill (Figure 8), there was a greater density of lung tissue.

Figure 6 shows the time course of central blood volume, lung water or ETV $_{\mathrm{L}}$, and $\mathrm{Pa}_{\mathrm{O}_{2}}$ as oedema progressed up to values of $35 \mathrm{ml} / \mathrm{Kg}$. Arterial oxygenation initially improves with congestion probably because of better perfusion to the well oxygenated top of the lung. As oedema begins to accumulate, arterial oxygenation falls but it is not until after oedema has increased by more than 72 per cent above control that $\mathrm{Pa}_{\mathrm{O}}$, falls off rapidly.

Films were taken with a 20.1 per cent (Figure 7), 74 per cent (Figure 8), and 318 per cent (Figure 9), increase in lung water above controls. At each increase 


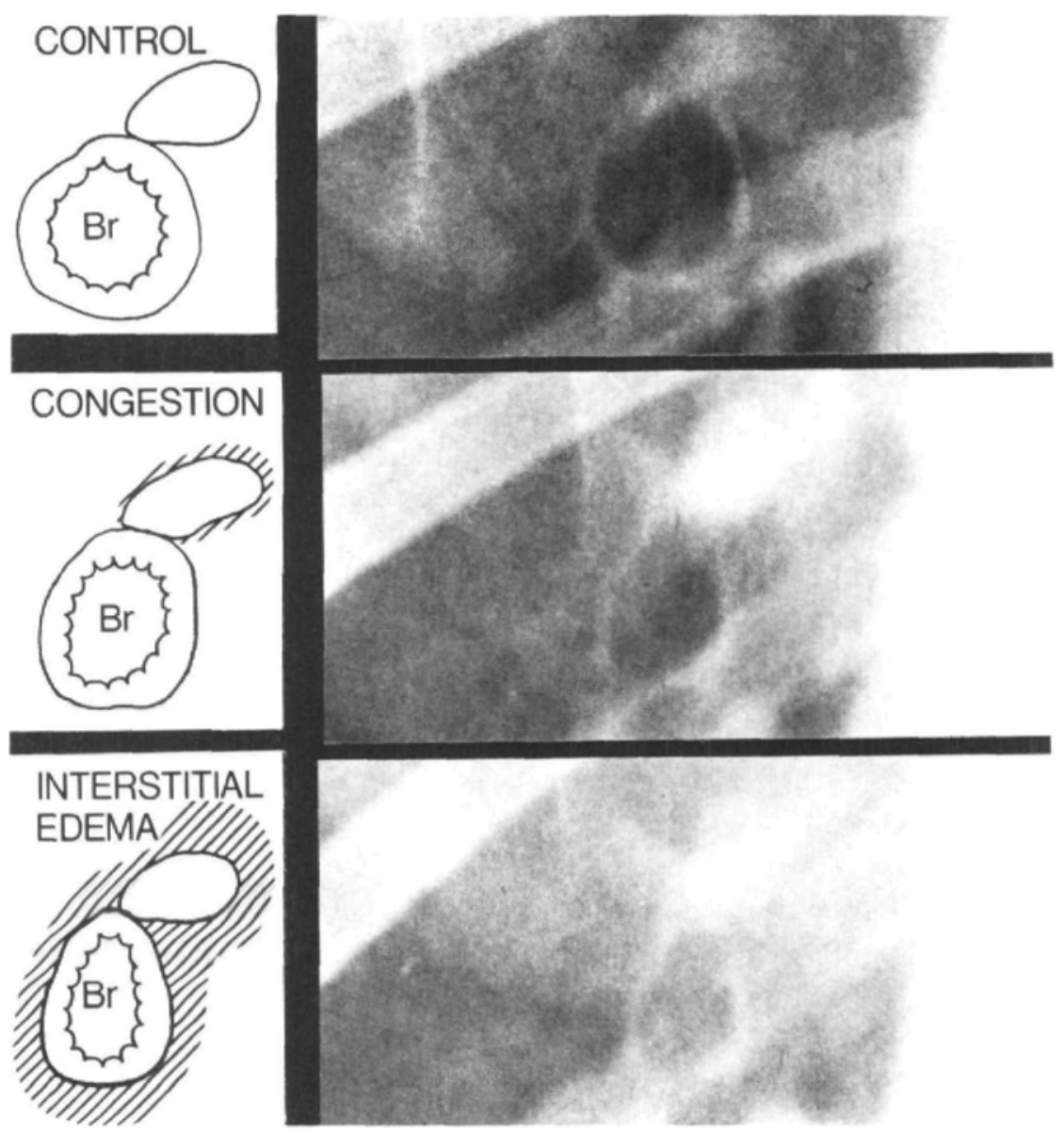

Ficune 5. The "end-on" bronchus and vessel from films number 1, 2 and 3 are enlarged. Beside them is a diagrammatic representation of an end-on bronchus ( $\mathrm{Br}$ ) and vessel. The earliest interstitial oedema is seen as haziness of the hilar area.

of lung water the films change from vein blurring to greater and greater density of lung tissue. Air bronchograms appear as alveoli fill with fluid and the oxygen tension falls.

We fully expected the lateral films (Figures 10,11, 12,13) to be helpful in detecting early oedema but this did not occur. The early oedema film (Figure 12) was hard to detect in the lateral projection because the high density heart and vertebrae made it impossible to see vessels. In gross oedema (Figure 13), air bronchograms are easily seen on the lateral film.

Figure 6 indicates the changes which occurred when CPPV was applied at the end of the experiment. Lung water did not fall. In fact, it continued to progress as if CPPV had never been applied. Central blood volume fell dramatically and arterial oxygenation rapidly rose to control levels.

The films No. 7 indicate the changes which occurred after CPPV was applied (Figures 14, 15). The airways were dilated, the lung enlarged, and gas was forced 

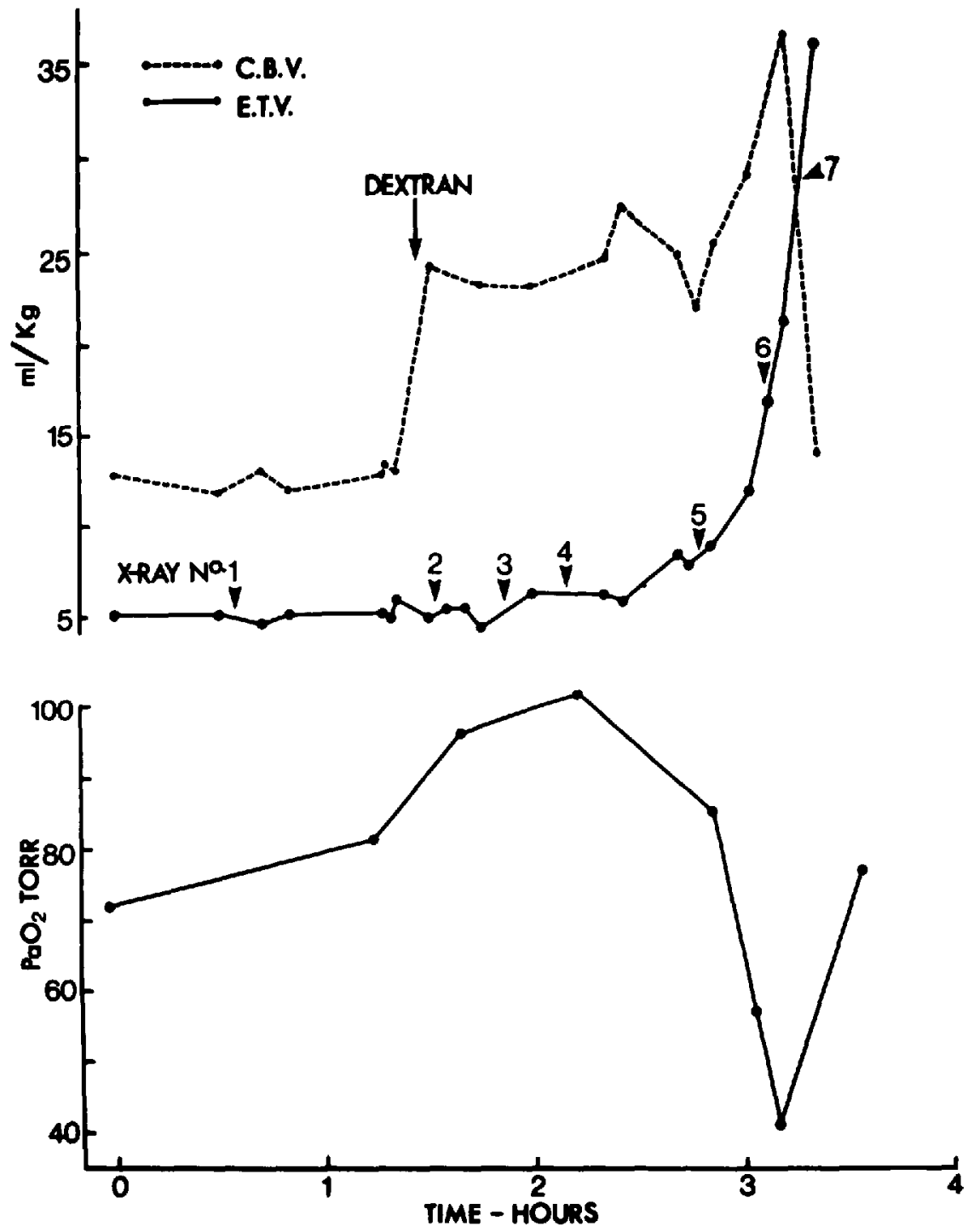

Figure 6. Changes in CBV, $\mathrm{ETV}_{\mathrm{L}}$ (lung water) and $\mathrm{Pa}_{\mathrm{O}_{2}}$ as dextran was infused (after arrow). Films were taken at the indicated times. CPPV was applied just before film number 7 and the last values.

into the lower lobes which were still oedematous. The major effect of CPPV seen here is an increase in FRC to improve arterial oxygenation.

\section{Discussion}

No technique prior to ETV $_{\mathrm{I}}$ would allow frequent, rapid quantitation of lung water. ETV $_{\mathrm{L}}$ allowed us to compare small changes in lung water with lung radiographic changes. We have attempted to separate radiographic changes into 


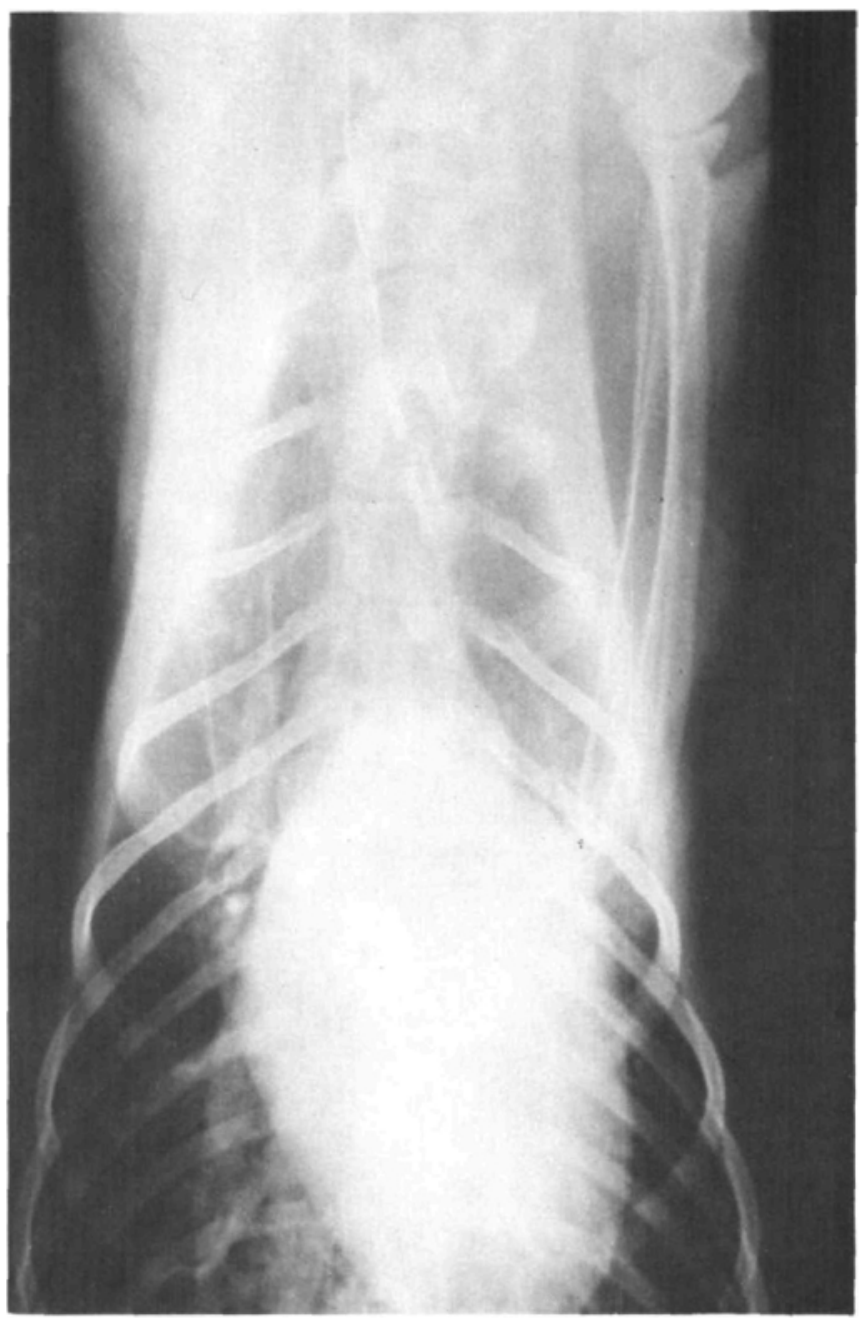

Figure 7. Film number 4 was taken with a 20.1 per cent increase in lung water. There is only a slight increase in lung density which is considered to represent interstitial oedema.

engorgement or congestion, interstitial oedema and alveolar oedema stages. Although these stages are described separately the lines between them cannot be clearly drawn. In one portion of the lung congestion may exist while interstitial oedema or alveolar oedema may occur in others. For this reason and because the full capillaries of congestion may create some haziness it is not easy to separate congestion from early interstitial oedema on radiographs.

The earliest phase of pulmonary oedema seen by electron microscopy is in the interstitium. ${ }^{7}$ This compartment is continuous with the loose connective tissues surrounding conducting airways and vessels. The appearance of fluid in this compartment occurs before there is any evidence of alveolar filling and the alveolar wall thickness is almost normal. On radiographs this fluid is seen as haziness of the large vessels. Figures 2, 3 and 4 show progressively more vessels, presumably due 


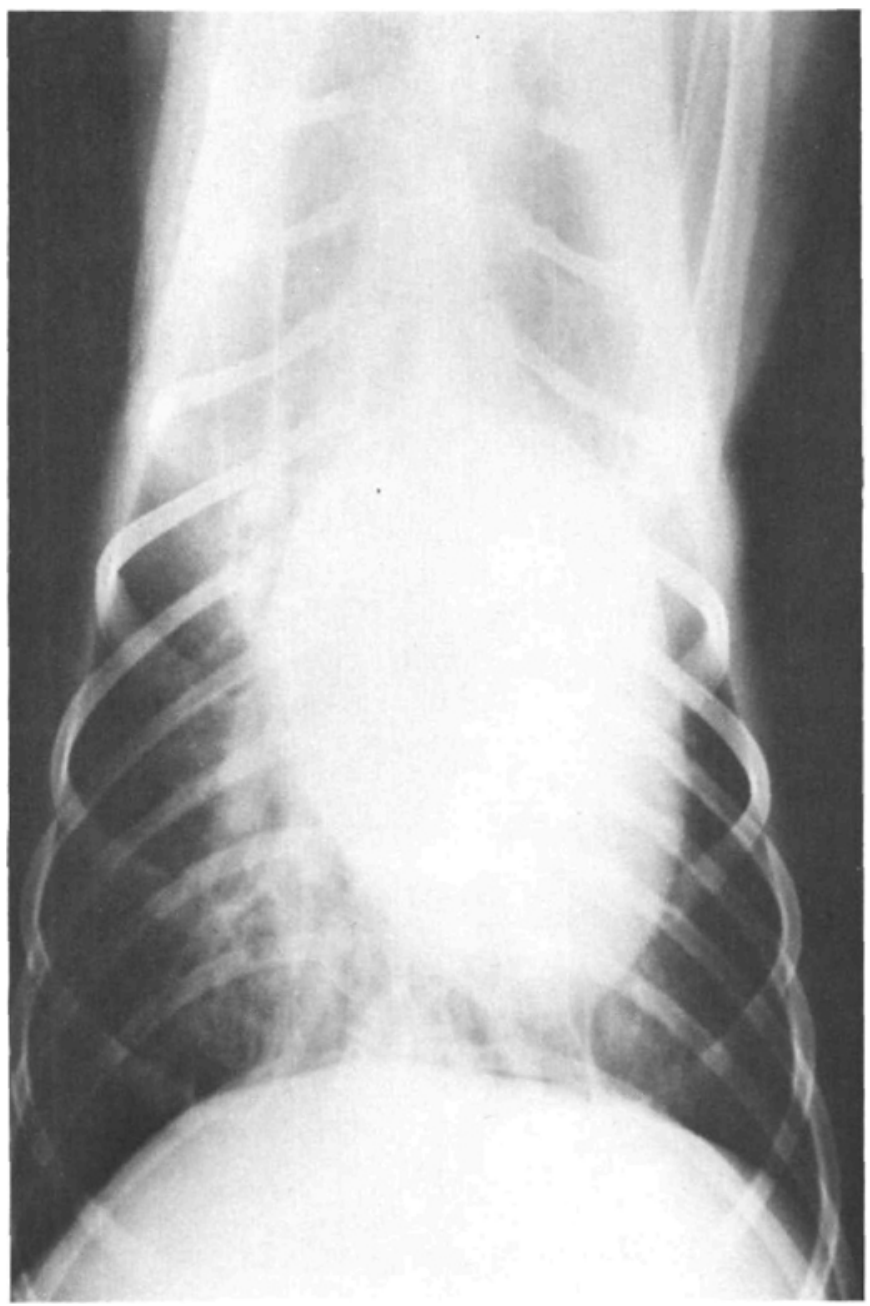

Figure 8. Film number 5 was taken with a 74 per cent increase in lung water. Pao fall at this point and the increased lung density indicates alveolar filling is occurring.

to engorgement of existing vessels and some perivascular and peribronchial cuffing as dextran was infused. The improvement in arterial oxygen tension at the same time must result from increased perfusion of well ventilated alveoli. Thickening of the alveolar wall would not be recognizable by the radiologist as this is thickening only up to 3 microns.

Lymphatics were never seen. This may indicate a peculiarity of the dog or may be a result of our method of inducing pulmonary oedema. Perhaps a more chronic form of pulmonary oedema would allow lymphatics to fill. Of course it is possible that some of the background shadowing represents lymphatic dilatation.

The final phase of pulmonary oedema is the filling of the alveoli. This is seen radiographically as a generalized increase in the density of lung tissue and an air bronchogram. The absence of trapped gas or bubbles within the alveoli is strong 


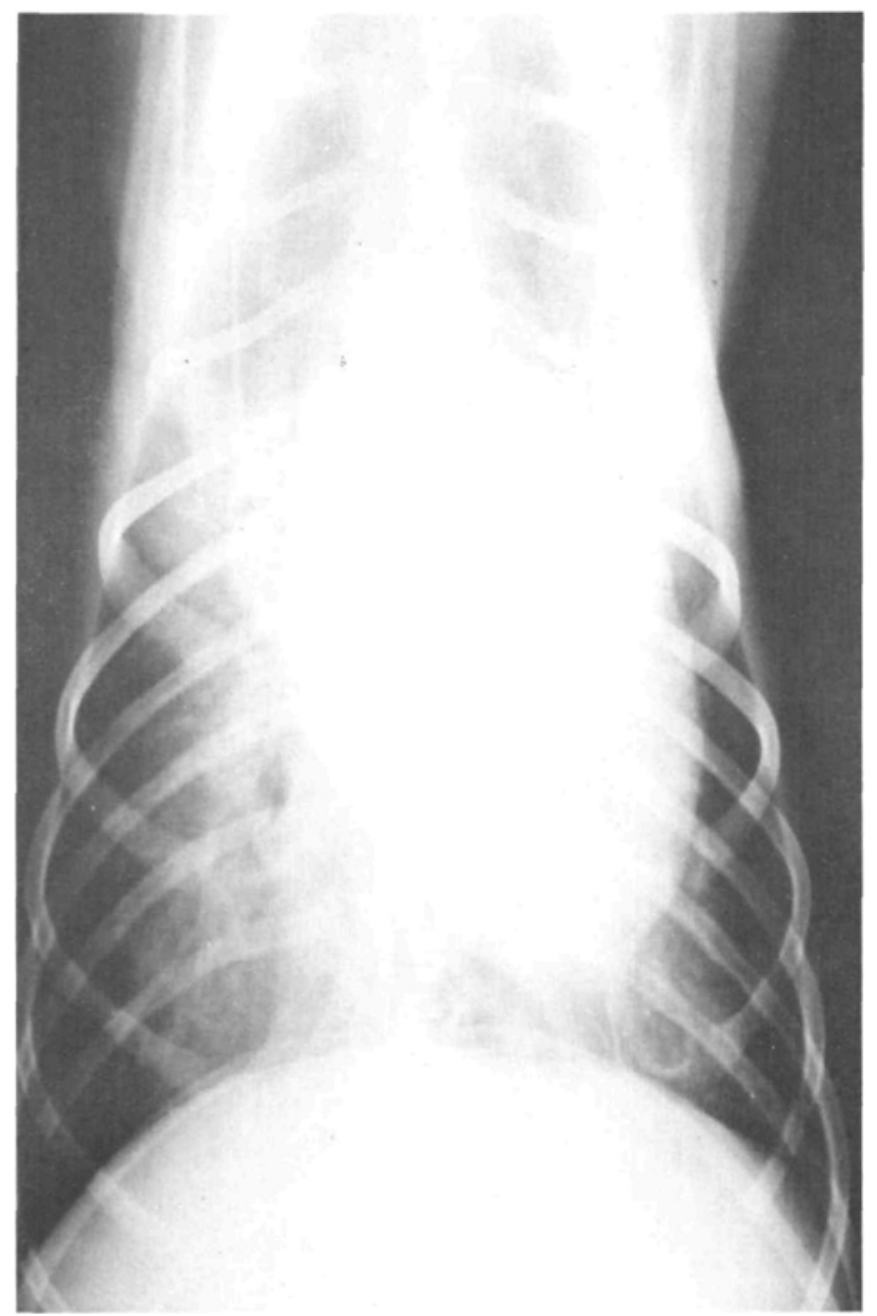

Figure 9. Film number 6 was taken with a 318 per cent increase in lung water. The myocardial outline is becoming blurred and the lung tissue quite dense.

evidence for an orderly process of alveolar filling. Each alveolus was either normal (air-filled), or oedema-filled with reduced volume, or collapsed. This accounts for the fall in arterial oxygenation as shunts developed past unventilated alveoli. It also readily explains why forced inflation of the lungs with CPPV in oedema improves arterial oxygenation even though fluid is not removed from the lung.

\section{SUMMARY}

Chest radiographs taken under ideal conditions and reviewed by a radiologist experienced in looking for pulmonary oedema are an accurate technique for detecting early oedema, differentiating between congestion and oedema, monitoring the increases in oedema up to the stage of alveolar flooding and in determining the effects of CPPV on an oedematous lung. However, ideal conditions do not exist 


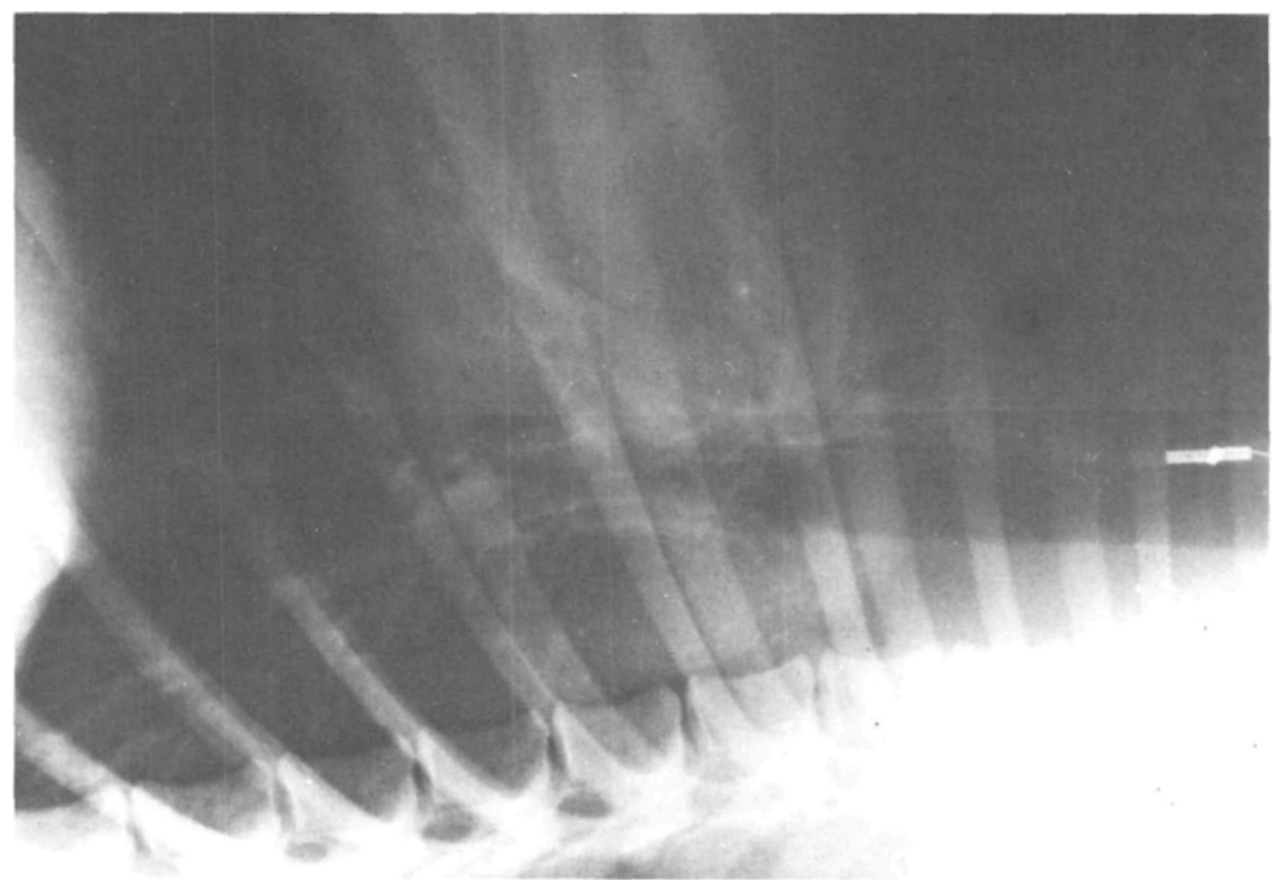

Frgure 10. Film number 1 lateral in the control period indicates the vertebrae at the lower edge, the peak of the diaphragm at the left, the trachea on the right and the end of the aortic catheter at the right edge.

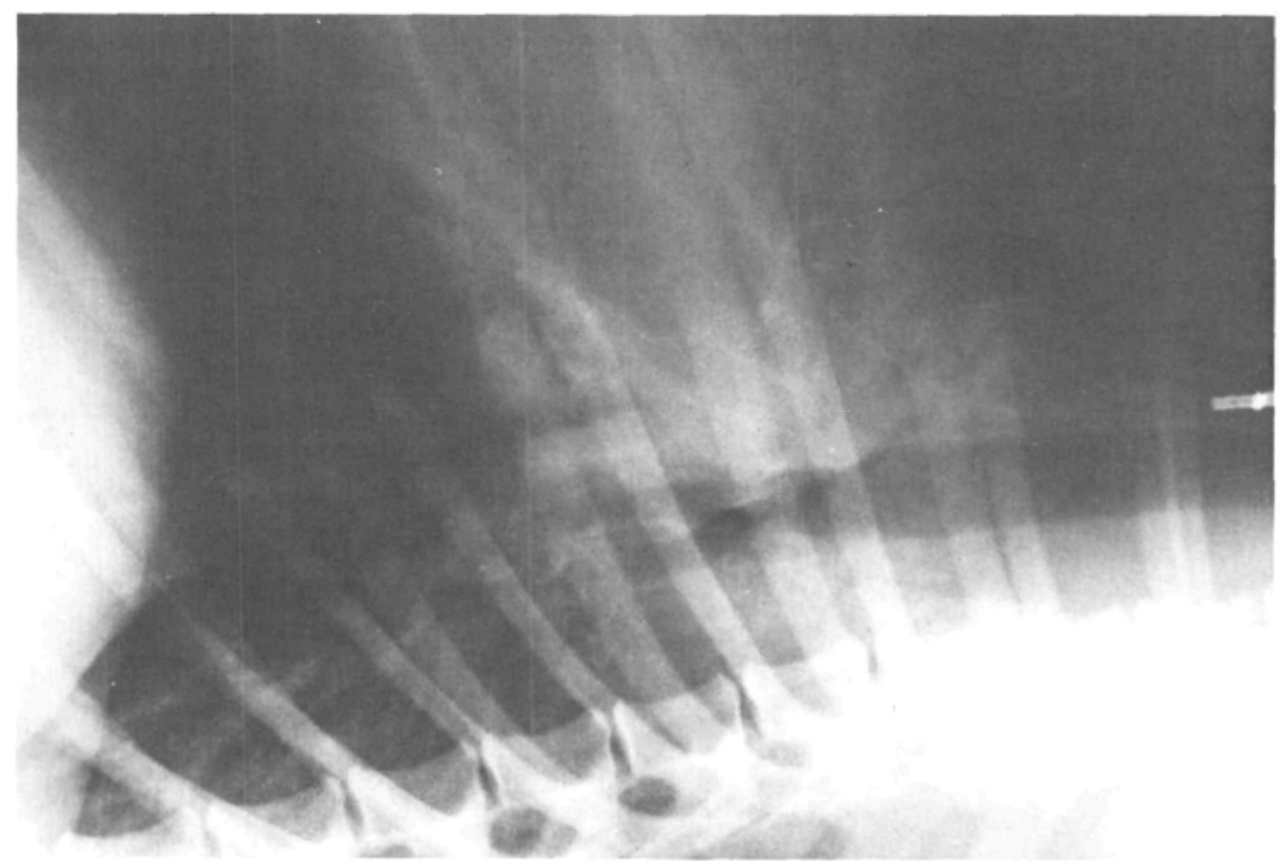

Figure 11. Film number 2 lateral in congestion shows dilated vessels and no haziness. 


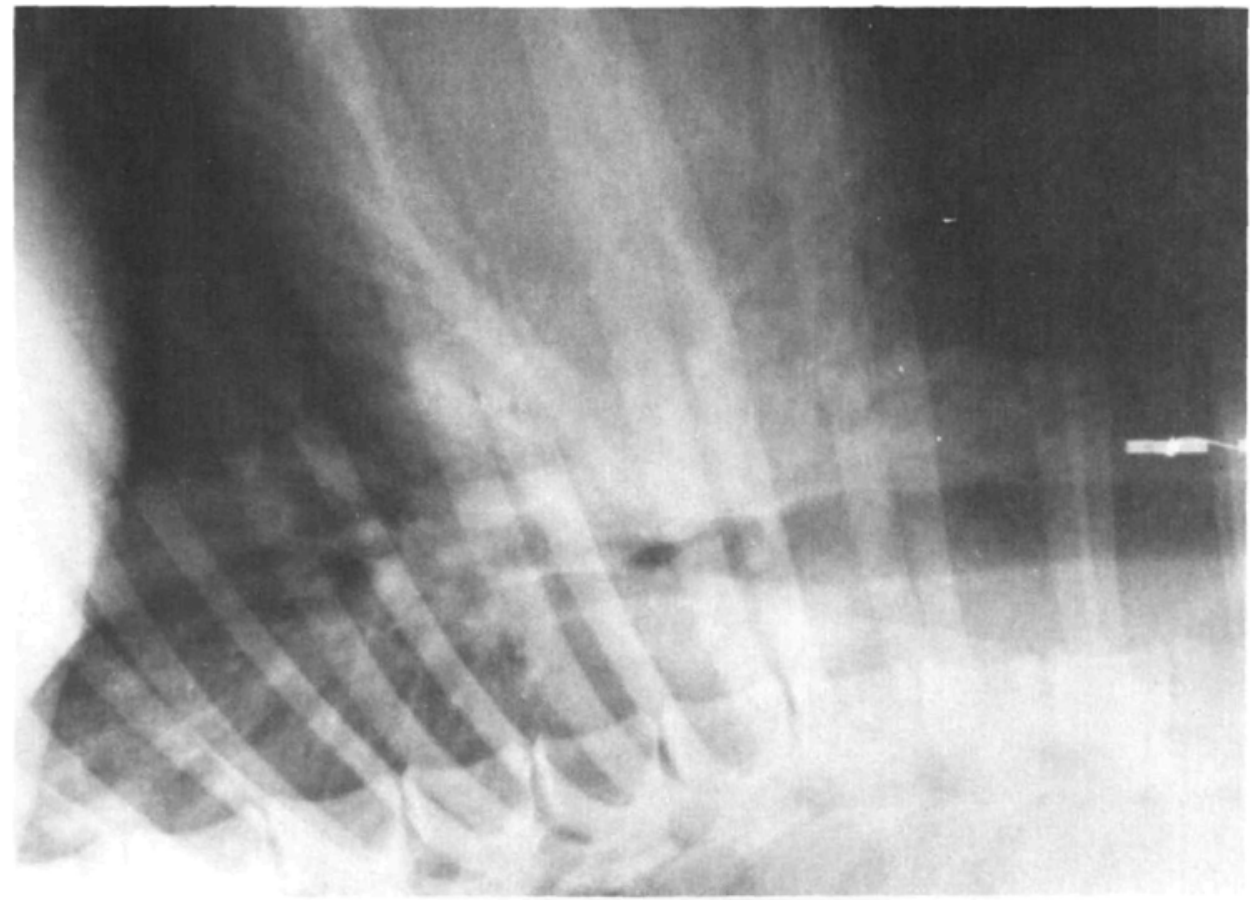

FIGURE 12. Film number 3 lateral in early interstitial oedema.

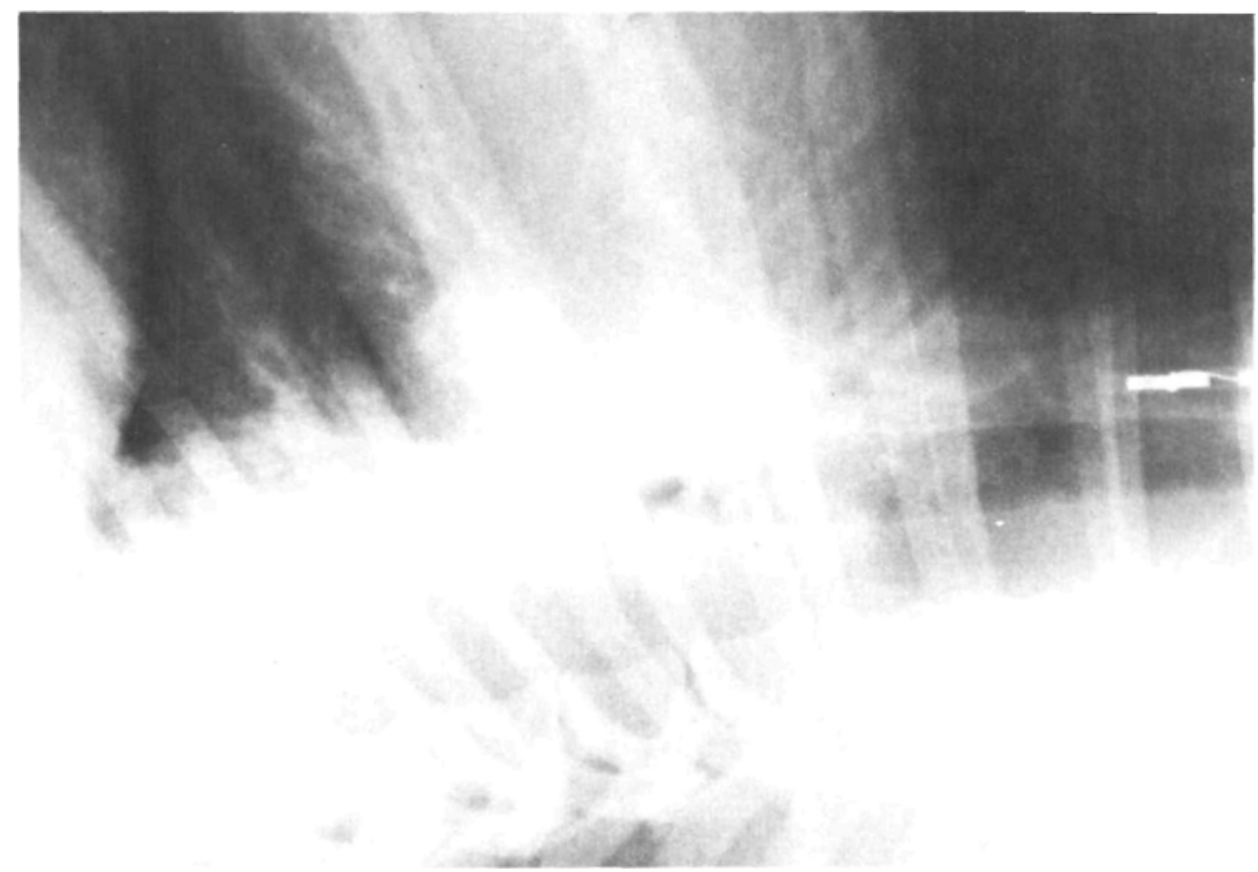

Figure 13. Film number 6 lateral in gross oedema indicates air bronchograms and almost total lack of air in the posterior lung. 


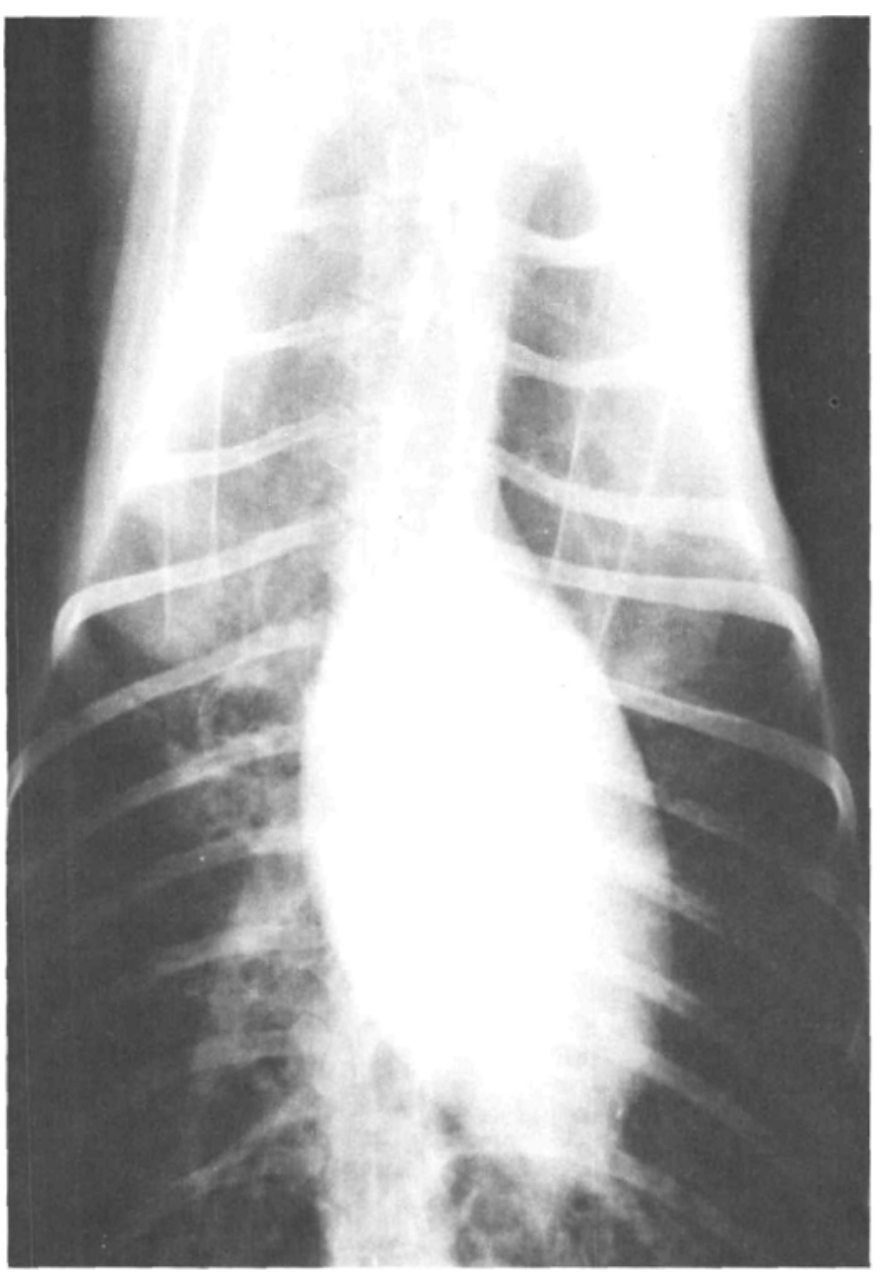

Frgure 14. A-P film number 7 in gross oedema after $15 \mathrm{~cm} \mathrm{H} \mathrm{H}_{2} \mathrm{O}$ end tidal pressure was applied to produce CPPV.

in the I.C.U. Our radiologist had the advantage of a fast exposure, a normal film for comparison in the sequence and only one lesion, conditions unlikely to occur in the I.C.U. It becomes apparent that it is important to obtain the best possible image in these complicated patients. Films in the erect position, for vascular distribution, as well as fast exposures with a high MAS factor give the sharp detail required to best assess lung changes. Serial studies of the chest are a requirement of the I.C.U. patient and it is helpful if comparable films are obtained by using a fixed target-to-film distance in association with the short exposure factors. If this care is taken, chest radiographs are the most accurate non-invasive technique for detecting pulmonary oedema.

\section{RÉSUMÉ}

La radiographie pulmonaire effectuée dans des conditions idéales et interprétée 


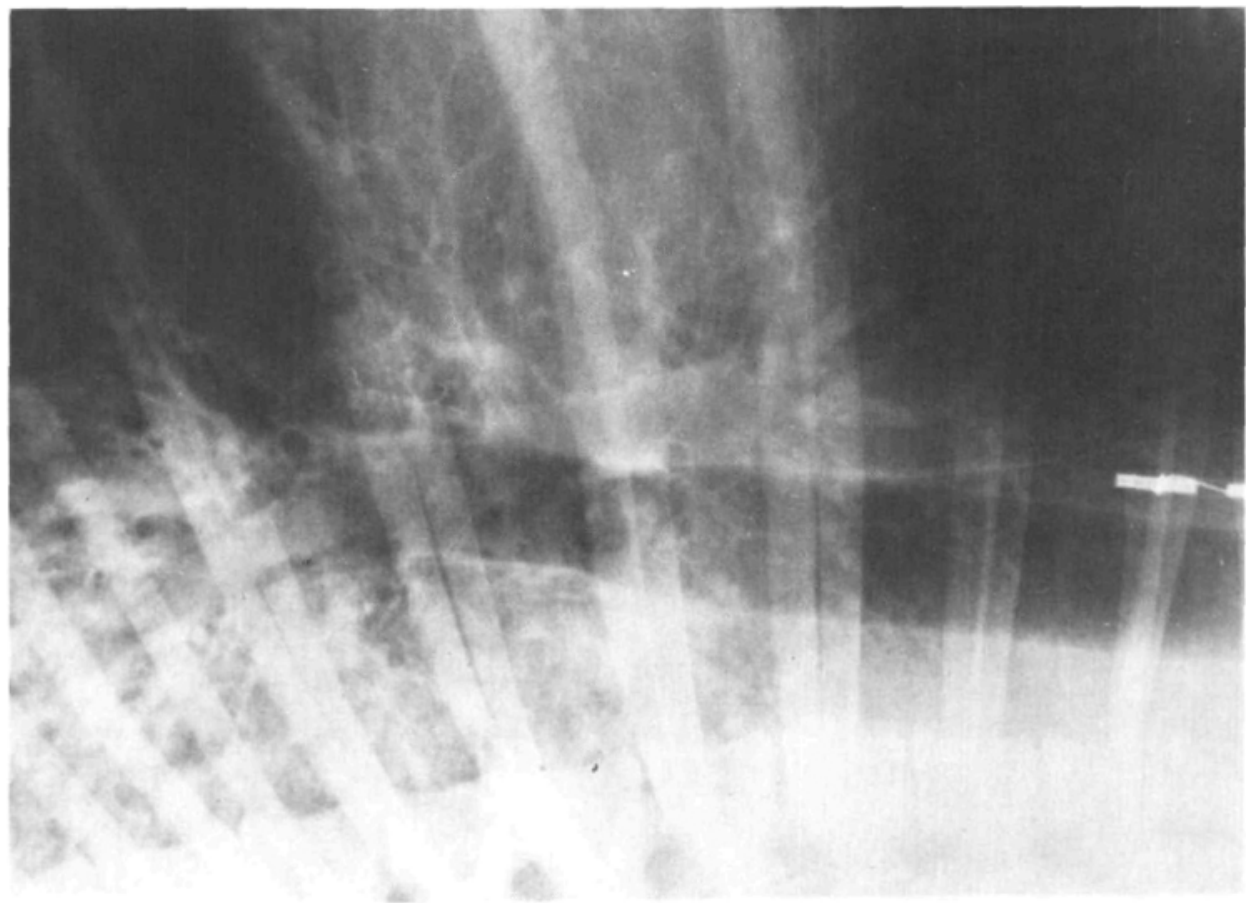

Figure 15. Lateral film number 7 after CPPV.

par un radiologiste habitué à rechercher l'œdème pulmonaire est une méthode précise de détecter l'œdème dès son début, de différencier hypertension veineuse et œdème, de suivre les degrés d'œdème jusqu'au stage de remplissage alvéolaire et d'évaluer les effets de la PEEP sur un poumon œedémateux.

Ces conditions idéales n'existent pas chez les patients hospitalisés dans les unités de soins intensifs. Notre radiologiste avait l'avantage d'une technique d'exposition rapide, de la disponibilité d'un film antérieur normal pour fins de comparaisons et de l'existence d'une seule pathologie à interpréter, conditions qui existent rarement chez des malades hospitalisés dans les unités de soins intensifs.

La nécessité d'obtenir des films de la plus haute qualité possible nous est apparue clairement. La prise des films en position verticale permettant d'évaluer la distribution de la vascularité pulmonaire et un temps d'exposition court, avec milliampérage/seconde élevé, permettant d'obtenir la netteté de détail nécessaire à une interprétation précise. Des films successifs sont nécessaires pour évaluer la progression de la pathologie et l'on pourra obtenir des films comparables en gardant constante la distance patient-film ainsi qu'une exposition courte.

La radiographie pulmonaire effectuée dans ces conditions est la technique non invasive la plus efficace de détection de l'œdème pulmonaire.

\section{ACKNOWLEDGMENTS}

We gratefully acknowledge the expert technical assistance of Mr. J.C. Kay, 
Mrs. Donna Joy Toelle, Mr. G. Carmichael, Mr. A. Janetta, Miss Mary-Jo Murphy and Mr. Dennis Poulin.

Nembutal was supplied by Abbott and Dextran by Pharmacia (Canada).

This work was supported by the Medical Research Council of Canada Grant MA 4263, the Ontario Thoracic Society and the Canadian Tuberculosis and Respiratory Disease Association.

\section{REFERENCES}

1. Chinaro, F.P. \& Enns, T. Trans capillary pulmonary exchange of water in the dog. Am. J. Physiol. 178: 197-202 (1954).

2. Noble, W.H. \& Severinghaus, J.W. Thermal and conductivity dilution curves for rapid quantitation of pulmonary oedema. J. Applied Physiol. 32: 770-775 (1972).

3. NoBle, W.H., OBdrzalek, J., \& KaY, J.C. A new technique for measuring pulmonary oedema. J. Applied Physiol. 34: 508-512 (1973).

4. Noble, W.H., KaY, J.C., \& ObdrzaleK, J. Lung mechanics in hypervolemic pulmonary oedema and the effect of CPPV. Submitted J. Applied Physiol.

5. Milne, E. Correlation of physiologic findings with chest roentgenology. Radiologic Clinics of North America. 11: 17-47 (1973).

6. Staub, N.D., Necano, H., \& Pearce, M.L. Acute pulmonary oedema in dogs, especially the sequence of fluid accumulation in the lungs. J. Applied Physiol. 22: 227-240 (1967).

7. Noble, W.H., Kovacs, K., \& KAY, J.C. Fine structural changes in haemodynamic pulmonary oedema. C.A.S.J. $21: 275-284$ (1974). 